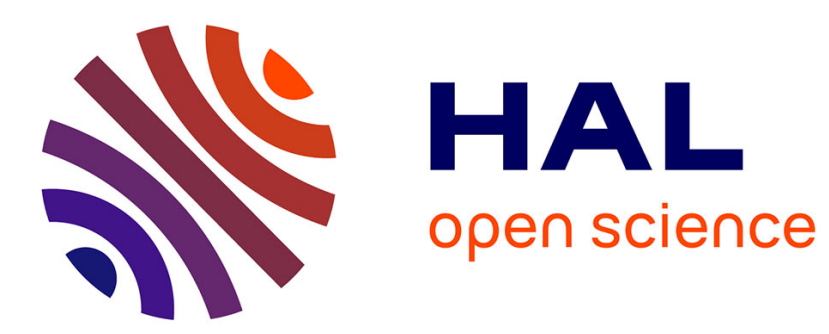

\title{
On the origin of the enhancement of defect related visible emission in annealed $\mathrm{ZnO}$ micropods
}

Anisha Gokarna, Roy Aad, Junze Zhou, Komla Nomenyo, Alain Lusson, Patrice Miska, Gilles Lerondel

\section{- To cite this version:}

Anisha Gokarna, Roy Aad, Junze Zhou, Komla Nomenyo, Alain Lusson, et al.. On the origin of the enhancement of defect related visible emission in annealed $\mathrm{ZnO}$ micropods. Journal of Applied Physics, 2019, 126 (14), pp.145104. 10.1063/1.5111184 . hal-02314872

HAL Id: hal-02314872

https://hal-utt.archives-ouvertes.fr/hal-02314872

Submitted on 17 Dec 2020

HAL is a multi-disciplinary open access archive for the deposit and dissemination of scientific research documents, whether they are published or not. The documents may come from teaching and research institutions in France or abroad, or from public or private research centers.
L'archive ouverte pluridisciplinaire HAL, est destinée au dépôt et à la diffusion de documents scientifiques de niveau recherche, publiés ou non, émanant des établissements d'enseignement et de recherche français ou étrangers, des laboratoires publics ou privés. 


\title{
On the origin of the enhancement of defect related visible emission in annealed $\mathrm{ZnO}$ micropods
}

Cite as: J. Appl. Phys. 126, 145104 (2019); doi: 10.1063/1.5111184

Submitted: 24 May 2019 - Accepted: 18 September 2019 .

Published Online: 8 October 2019

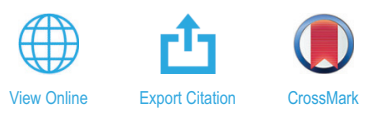

Anisha Gokarna, ${ }^{1, a), b)}$ Roy Aad, ${ }^{1, a), c)}$ Junze Zhou, ${ }^{1, a)}$ Komla Nomenyo, $^{7}$ Alain Lusson, ${ }^{2}$ (D) Patrice Miska, ${ }^{3, d)}$ (iD) and Gilles Lerondel ${ }^{1, b)}$ (iD

\author{
AFFILIATIONS \\ 'Lumière, Nanomatériaux, Nanotechnologie, Institut Charles Delaunay, CNRS, Université de Technologie de Troyes, \\ 12 rue Marie Curie, BP 2060, 10010 Troyes, France \\ ${ }^{2}$ Groupe d'Etude de la Matière Condensée, Université de Versailles, Saint Quentin en Yvelines, CNRS, Université Paris-Saclay, \\ 45 Avenue de Etat Unis, 78035 Versailles, France \\ ${ }^{3}$ Institut Jean Lamour - CNRS UMR 7198 - Université de Lorraine, Faculté des Sciences et Technologies, BP 70239, \\ F-54506 Vandoeuvre les Nancy, France

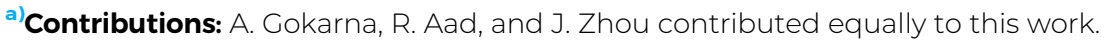 \\ ${ }^{\text {b)} E l e c t r o n i c ~ a d d r e s s e s: ~ a n i s h a . g o k a r n a @ u t t . f r ~ a n d ~ g i l l e s . l e r o n d e l @ u t t . f r ~}$ \\ ${ }^{c}$ Present address: Department of Natural Sciences, Lebanese American University, P. O. Box 36, Byblos, Lebanon. \\ d)This article is a homage to Dr. Patrice Miska from Institute Jean Lamour, Nancy, France, with whom we had a very good \\ scientific collaboration. Unfortunately, he passed away last year in his prime. His untimely demise has created a void in the \\ scientific community.
}

\begin{abstract}
We report an in-depth analysis of $\mathrm{ZnO}$ micropods emission. A strong correlation between defect and interband emissions is observed. $\mathrm{ZnO}$ micropods were grown using low-temperature chemical bath deposition (CBD). ZnO micropods exhibited perfectly-crystalline hexagonallyshaped facets with various numbers of branches. Raman studies showed that $\mathrm{ZnO}$ micropods contained trapped zinc hydroxide $(\mathrm{OH})$ and imidogen $(\mathrm{NH})$ defects that originate from the precursor solution used in the CBD technique. These defects were evacuated by thermal annealing, leading to the recrystallization in the volume of the micropods and the formation of structural defects at their surface, as attested by scanning electron microscopy and X-ray diffraction. More importantly, the thermal annealing was accompanied by a breakdown of the $\mathrm{NH}$ defects, which resulted in a nitrogen doping of the $\mathrm{ZnO}$ micropods. The structural changes as well as the nitrogen doping resulted in a drastic change in the photoluminescence (PL) spectrum of the $\mathrm{ZnO}$ micropods that exhibited a stronger free exciton UV emission as well as a stronger visible (white) emission. An in-depth low-temperature PL study of both UV and visible emission reveals a strong interplay between the structural-defect bound excitonic UV emission (Y-band) and the deep donor (visible) emission, which suggests a rather complex emission mechanism involving an efficient nonradiative energy transfer between the Y-band states and defect states leading to the enhanced visible emission of $\mathrm{ZnO}$ micropods after high temperature annealing.
\end{abstract}

Published under license by AIP Publishing. https://doi.org/10.1063/1.5111184

\section{INTRODUCTION}

Zinc oxide ( $\mathrm{ZnO})$, a II-VI semiconducting compound oxide with a direct bandgap of $3.37 \mathrm{eV}$ and a high exciton binding energy of $60 \mathrm{meV}$ at room temperature, is an important semiconductor due to its remarkable optical, electrical, and piezoelectrical properties, which can be widely used in optoelectronic and photovoltaic devices. ${ }^{1,2}$ Using this material, one can easily grow the desired nanostructures for the fabrication of functional 
devices such as light-emitting diodes, ${ }^{3-5}$ field-effect transistors, ${ }^{6-8}$ ultraviolet lasers, ${ }^{9-11}$ chemical sensors, ${ }^{12-15}$ and solar cells. ${ }^{16-18}$ High optical gain $\left(>1000 \mathrm{~cm}^{-1}\right)$ observed in $\mathrm{ZnO}$ epilayer ${ }^{19}$ also allows for a new kind of gain assisted energy transfer. ${ }^{20}$ In addition to remarkable physical properties, $\mathrm{ZnO}$ can be grown on any kind of surfaces or structures, ${ }^{21}$ especially rounded surfaces like spheres leading to original urchins type of heterostructures. ${ }^{22,23}$ To date, $\mathrm{ZnO}$ micro- and nanostructures such as quantum dots, nanorods, nanotubes, nanosheets, and nanoflowers have all been successfully prepared by either using physical deposition or chemical methods. ${ }^{24-26}$ In comparison to physical methods, solution based methods are appealing for their cheap experimental setups, large scale productivity, and low-temperature synthesis. Chemical bath deposition (CBD) is one of the useful methods for the preparation of compound semiconductors from aqueous solution with advantages such as low processing temperature, allowing growth on a variety of substrates, and easy adaptation to large area processing at a low cost of fabrication. Large scale and low cost are also two of the main prerequisites for the realization of $\mathrm{ZnO}$ based devices for industrial production. Controlled growth of nano- or microstructures in terms of size, shape, and orientation is also an important factor in device fabrication, and a large amount of intensive research has been conducted to prepare desired $\mathrm{ZnO}$ architectures. There are a few articles that which report the synthesis of two types of twinned structures of $\mathrm{ZnO}$ (like the micropods reported here) prepared by the hydrothermal technique. ${ }^{27-30}$ The twinned crystallites that were synthesized in pure water or weak basic solutions such as $1 \mathrm{~N} \mathrm{KOH}$ were bipyramidal, whereas the twinning morphology of the crystallites obtained from $4 \mathrm{~N} \mathrm{KBr}$ or $3 \mathrm{~N} \mathrm{NaNO}_{2}$ solutions were dumbbell-like. ${ }^{28}$ These articles lay emphasis on the growth mechanisms of these twinned structures. They demonstrated that the formation of twin morphologies of $\mathrm{ZnO}$ crystallites is either a result of differences between symmetrical and energetic most favorable structural arrangements or due to the consequence of oriented intergrowths.

The growth mechanism of $\mathrm{ZnO}$ microstructures as well as their photoluminescence (PL) spectra has been widely studied and reported. However, there are still no reports on a comprehensive in-depth analysis, which investigates the mechanism that underlies the emission spectrum. In this study, we synthesize highly crystalline, hexagonal shaped $\mathrm{ZnO}$ micropods by a simple low-temperature, low-cost chemical bath deposition technique. As-grown $\mathrm{ZnO}$ micropods were afterward thermally annealed under argon atmosphere to evacuate Zinc hydroxide defects. In-depth scanning electron microscope (SEM) and X-ray diffraction (XRD) reveal that the annealing process leads to recrystallization of the micropods volume together with the formation of structural defects at the surface. Room-temperature photoluminescence of annealed micropods exhibits a free exciton (FX) peak and notable change in the intensity of the $\mathrm{ZnO}$ defect emission in the visible, as compared to the as-grown samples. In-depth temperature-dependent PL measurements reveal a negative thermal quenching (NTQ) of the nitrogen-bound defect emission, which is evidence of an energy transfer process. An efficient nonradiative energy transfer mechanism between structural-bound defect emission and nitrogen-bound deep donor emission is proposed to explain the drastic increase of the visible emission of $\mathrm{ZnO}$ micropods.

\section{EXPERIMENTAL DETAILS}

\section{A. Synthesis of $\mathrm{ZnO}$ micropods}

In a typical series of experiments, the precursor solution used consisted of Zinc acetate dihydrate $\left(\mathrm{Zn}\left(\mathrm{CH}_{3} \mathrm{COO}\right)_{2} \cdot 2 \mathrm{H}_{2} \mathrm{O}\right.$, ACS reagent, $\geq 98 \%$ ), ammonium hydroxide $\left(\mathrm{NH}_{3}\right.$ basis, ACS reagent, $28 \%-30 \%)$ and deionized water. Undoped p-type (100) silicon wafers having a resistivity of $1-5 \Omega \mathrm{cm}$ and a thickness of $250 \mu \mathrm{m}$ are used for depositing the micropods. It is important to note that micropods grow freely in the solution and can be deposited on any substrate; in our case, we selected silicon. These micropods deposited on the silicon substrate are free-standing. The growth of the $\mathrm{ZnO}$ micropods is conducted by the chemical bath deposition technique. For preparing the solution, $0.056 \mathrm{M}$ zinc acetate is dissolved in $250 \mathrm{ml}$ of water. $1 \mathrm{ml}$ of ammonium hydroxide is added to this solution and stirred at room temperature. Synthesis is conducted in the absence of metal catalysts or additives. This mixed solution is heated at $87^{\circ} \mathrm{C}$ in a three neck round bottom flask. The cleaned silicon substrate is immersed in this solution for a time period of $2 \mathrm{~h}$. Thereafter, the sample is washed with water and dried in air. Two types of samples are used in this study. One is an as-grown sample and the other is an annealed sample.

\section{B. Annealing of the micropods}

Annealing of the sample was conducted at $900^{\circ} \mathrm{C}$, in a nitrogen atmosphere in a rapid thermal annealing system for a time period of $10 \mathrm{~min}$.

\section{Structural and optical characterization}

The $\mathrm{ZnO}$ micropods and their surface morphology were examined using a scanning electron microscope (SEM, HITACHI S-3400N, $30 \mathrm{kV}$ ). Phase identification of the micropods was done with a Philips powder X-ray diffractometer equipped with a $\mathrm{Cu} \mathrm{K \alpha}$ line. Temperature-dependent photoluminescence (PL) experiments were conducted using a $\mathrm{He}-\mathrm{Cd}$ laser $(325 \mathrm{~nm})$ as an excitation source and a CCD camera as a detector. An unfocused laser beam was used for the PL studies. Liquid helium was used for cooling the sample down to $2 \mathrm{~K}$. An $80 \mathrm{~cm}$ focal length spectrometer with a 3200 lines/mm grating was used for high resolution PL spectroscopy. Micro-Raman measurements were conducted at room temperature using laser wavelength of $514 \mathrm{~nm}$ and a beam spot size of $1 \mu \mathrm{m}$.

\section{RESULTS AND DISCUSSION}

Figure 1 shows the morphologies of the as-grown $\mathrm{ZnO}$ micropods using SEM imaging. These micropods are free-standing. Silicon substrate serves as a support for these micropods. The average length of these micropods is observed to be $10-15 \mu \mathrm{m}$ and $1-5 \mu \mathrm{m}$ in diameter. One can clearly observe some micropods with two (bipods), four (tetrapods), six arms (hexapods) and cross-linked structures with many arms. Inset in the upper left hand side corner in Fig. 1 is an enlarged image of a few micropods. The micropods are observed to be perfectly hexagonal in structure, with very smooth sidewalls. However, after annealing at $900^{\circ} \mathrm{C}$, formation of pores is seen to occur on these arms, as seen in the inset in the lower right hand corner. 


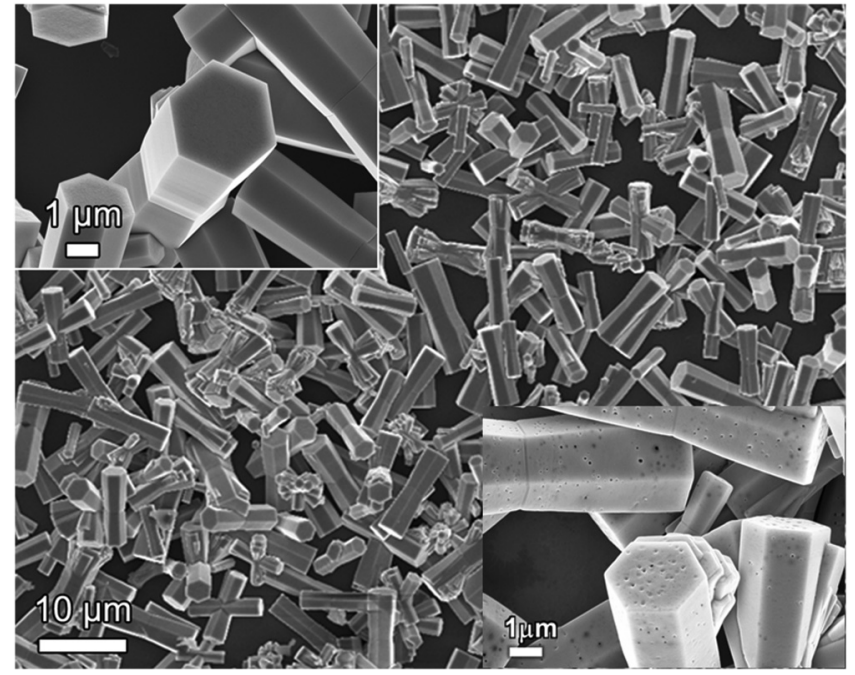

FIG. 1. SEM image of $\mathrm{ZnO}$ micropods consisting of two, four, or six arms. Inset in the upper corner shows a zoom-in image of the perfectly hexagonal micropods before annealing and in the lower corner after annealing where pores are observed.

One needs to understand the possible growth mechanism of these micropods and the driving force for the formation of these morphologies. The general chemical reactions occurring in the precursor solution are as follows:

$$
\begin{gathered}
\mathrm{Zn}\left(\mathrm{CH}_{3} \mathrm{COO}\right)_{2} \rightarrow \mathrm{Zn}^{2+}+2 \mathrm{CH}_{3} \mathrm{COO}^{-}, \\
\mathrm{NH}_{4} \mathrm{OH} \rightarrow \mathrm{NH}_{4}^{+}+\mathrm{OH}^{-}, \\
\mathrm{NH}_{4}^{+} \rightleftharpoons \mathrm{NH}_{3}+\mathrm{H}_{3} \mathrm{O}^{+}, \\
4 \mathrm{NH}_{3}+\mathrm{Zn}^{2+} \rightarrow \mathrm{Zn}\left(\mathrm{NH}_{3}\right)_{4}(\text { complex }), \\
\mathrm{CH}_{3} \mathrm{COO}^{-}+\mathrm{NH}_{4}^{+} \rightleftharpoons \mathrm{CH}_{3} \mathrm{COONH}_{4}(\text { complex }), \\
\mathrm{Zn}^{2+}+2 \mathrm{OH}^{-}+2 \mathrm{H}_{2} \mathrm{O} \rightarrow \mathrm{Zn}(\mathrm{OH})_{4}^{2-}+2 \mathrm{H}^{+}, \\
\mathrm{Zn}(\mathrm{OH})_{4}^{2-}+2 \mathrm{H}^{+} \rightarrow \mathrm{ZnO}+3 \mathrm{H}_{2} \mathrm{O} .
\end{gathered}
$$

In our synthesis process, the source of $\mathrm{OH}^{-}$ions is ammonium hydroxide, as seen in formula (2). More and more $\mathrm{OH}^{-}$ions will combine with $\mathrm{Zn}^{2+}$ ions to form a complex of $\mathrm{Zn}(\mathrm{OH})_{4}^{2-}$. This complex acts as an intermediate growth unit. Heating the solution along with the diffusion of ions results in the formation of $\mathrm{ZnO}$ clusters due to the dehydration reaction between $\mathrm{OH}^{-}$and $\mathrm{H}^{+}$. The important prerequisite for the formation of these micropods in the solution is that the solution should be supersaturated. When the solution is supersaturated, nucleation begins in the solution, which leads to the formation of $\mathrm{ZnO}$ micropods in the solution as reported for nanocrystals by $\mathrm{CaO}$ and $\mathrm{Cai}^{31}$
Majitha et al. have illustrated that when the solution is heated by using conventional techniques, the initial nucleation phase (which occurs in the solution) plays an important role in determining the growth mechanism of $\mathrm{ZnO}$ microstructures. ${ }^{32}$ When $\mathrm{Zn}^{2+}$ ions react directly with $\mathrm{OH}^{-}$ions to form $\mathrm{ZnO}$ (case of direct $\mathrm{ZnO}$ nucleation), crystal growth is presumed to occur by nanoparticle aggregation. The nanoparticles assemble along the $c$-axis of the wurtzite crystal resulting in an organized growth of the $\mathrm{ZnO}$ crystal. ${ }^{33-35}$ The different morphologies of microstructures such as tripods and tetrapods observed are generated by direct $\mathrm{ZnO}$ precipitation. Direct $\mathrm{ZnO}$ precipitation from an aqueous solution helps in twinning of structures, growth of multiple lattices from a common junction with individual crystals growing along their c-axes tetrahedral to each other, and leads to generation of tripod and tetrapod microstructures, as reported by Majitha et al. ${ }^{32}$ However, it is not possible to control the number of arms during the free-growth of these twinned structures in the solution.

To confirm the phase composition and the crystallinity of the synthesized micropods, we have conducted XRD pattern analysis. The XRD spectra of the as-grown and annealed $\mathrm{ZnO}$ micropods are shown in Fig. 2. Peaks corresponding to (100),

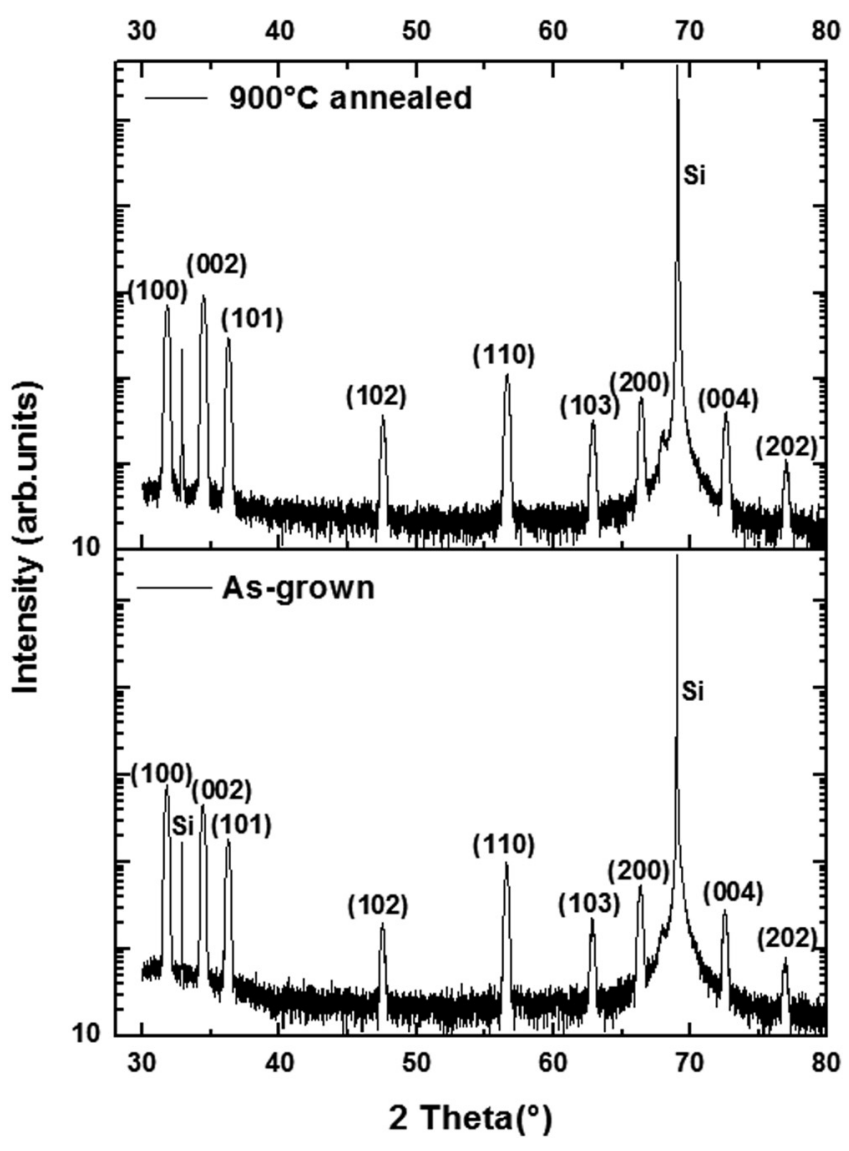

FIG. 2. XRD spectra (on a log scale) of as-grown micropods on silicon and $900^{\circ} \mathrm{C}$ annealed micropods. 
(002), (101), (110), (103), (102), (103), (200), (004), and (202) planes are observed.

All the peaks are attributed to the wurtzite hexagonal $\mathrm{ZnO}$ with the measured lattice constants $\mathrm{a}=3.20 \AA$ and $\mathrm{c}=5.207 \AA$. The strong and narrow diffraction peaks of the XRD pattern indicate that the as-grown samples are crystalline. After annealing, there is a further improvement in the crystallinity of the sample, which is evident from the enhancement in the intensity of the (002) peak and the (101) peak. The peaks observed at $32.5^{\circ}$ and the intense one at $69^{\circ}$ correspond to $\mathrm{Si}$. The crystallite sizes were also calculated using the Scherrer equation,

$$
\mathrm{D}=\frac{0.9 \lambda}{\mathrm{L} \cos \theta}
$$

where $\lambda=1.54 \mathrm{~A}^{\circ}, \mathrm{L}=$ full width at half maximum (FWHM) of the XRD peak, and $\theta$ is the Bragg's angle.

The FWHM of the (002) peak in the case of as-grown $\mathrm{ZnO}$ micropods is calculated to be $0.32^{\circ}$, whereas for the annealed sample, it is $0.15^{\circ}$. Thus, the FWHM of the (002) peak has reduced to nearly half of the value for the annealed micropods as compared to the as-grown sample. This is a clear evidence that the annealed micropods have become more crystalline. Taking these into account, the average crystallite size is $26 \mathrm{~nm}$ for the as-grown micropods sample and $55 \mathrm{~nm}$ for the annealed sample. The XRD pattern also indicates that the samples obtained via the CBD method consist of a pure phase of $\mathrm{ZnO}$. The crystalline quality of the two samples was investigated using Raman spectroscopy measurements (Fig. 3). For the two samples, the spectra exhibited various modes, namely, $2 \mathrm{E}_{2}(\mathrm{~L}), \mathrm{E}_{2}(\mathrm{H})-\mathrm{E}_{2}(\mathrm{~L}), \mathrm{A}_{1}(\mathrm{TO}), \mathrm{E}_{1}(\mathrm{TO})$, and $\mathrm{E}_{2}(\mathrm{H})$ modes at $203,333,378,410$, and $438 \mathrm{~cm}^{-1}$, respectively. In our spectral scan, we do not observe clearly the $\mathrm{E}_{2}(\mathrm{~L})$ mode as we started the scan at $100 \mathrm{~cm}^{-1}$. The $\mathrm{E}_{2}(\mathrm{~L})$ frequency mode relates with the vibration of heavy $\mathrm{Zn}$ atoms, while $\mathrm{E}_{2}(\mathrm{H})$ frequency mode reflects the vibrations of oxygen atoms in the $\mathrm{ZnO}$ crystal structure. Standard peak positions reported for $\mathrm{E}_{2}(\mathrm{~L})$ and $\mathrm{E}_{2}(\mathrm{H})$ modes in the case of bulk $\mathrm{ZnO}$ are 101 and $439 \mathrm{~cm}^{-1}$, respectively. ${ }^{36}$ From Fig. 3, one can clearly observe that the $\mathrm{E}_{2}(\mathrm{H})$ mode has considerably increased in intensity after annealing. Furthermore, the linewidth of the $\mathrm{E}_{2}(\mathrm{H})$ mode is $\sim 10 \mathrm{~cm}^{-1}$ for the as-grown and it drops to $7 \mathrm{~cm}^{-1}$ for the annealed sample. This further confirms that the micropods have an improved crystal quality after annealing. This is in good agreement with a general improvement of the crystalline quality, as determined by the XRD method too. We also performed a slow scan in the $3000-4000 \mathrm{~cm}^{-1}$ range for detecting the presence of $\mathrm{OH}$ groups or $\mathrm{Zn}(\mathrm{OH})_{2}$ groups and the $\mathrm{NH}$ groups (imidogen). These originate from the precursor solution during the CBD growth. We observe two strong, broad structured bands in the case of the as-grown sample in this range. This corresponds to the $\mathrm{OH}$ stretching mode and to the imidogen group. However, in the case of an annealed micropods sample, there is a complete absence of these structured bands as seen in Fig. 3.

Figure 4 shows the room-temperature PL spectra of the as-grown (a) and $900{ }^{\circ} \mathrm{C}$ annealed (b) micropods. Figure 4 reveals that annealing induces rather significant changes in both excitonic (UV) and defect (visible) emissions of $\mathrm{ZnO}$ micropods. The excitonic emission of as-grown $\mathrm{ZnO}$ micropods [Fig. 4(a)] presents a broad emission band with a peak at $385 \mathrm{~nm}(\sim 3.22 \mathrm{eV})$. A weak emission peak at $375 \mathrm{~nm}$ is also observed on the rising edge of the UV-band edge emission. On the other hand, the excitonic emission of annealed $\mathrm{ZnO}$ micropods [see Fig. 4(b)] shows a main emission band with a peak at $387 \mathrm{~nm}(\sim 3.204 \mathrm{eV})$ and a weaker emission band, observed at the high-energy shoulder of the NBE emission band [Fig. 4(b) inset], with a peak at $375 \mathrm{~nm}(\sim 3.306 \mathrm{eV})$. The

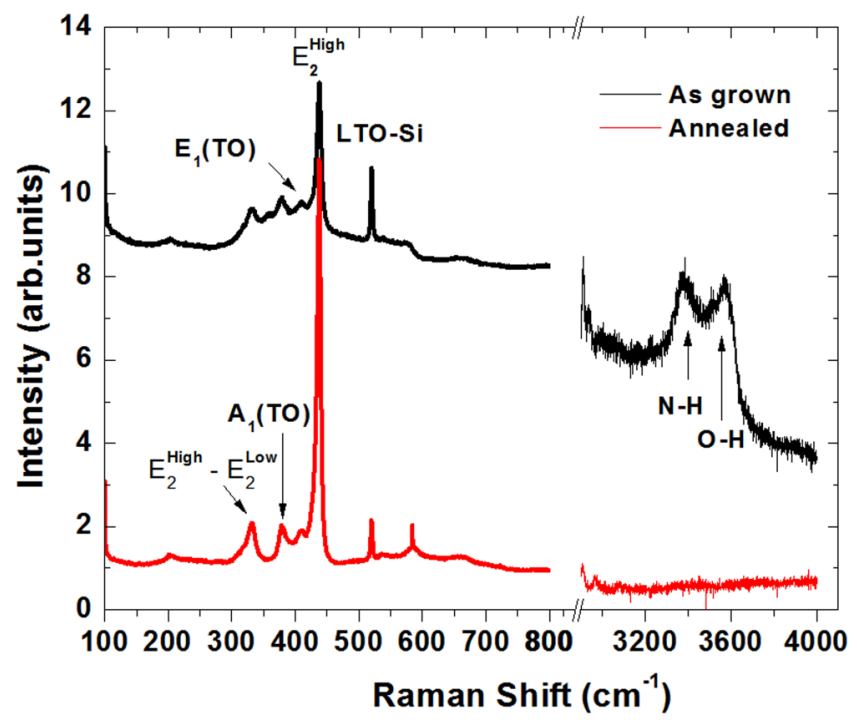

FIG. 3. Entire Raman spectra of the micropods before and after annealing.

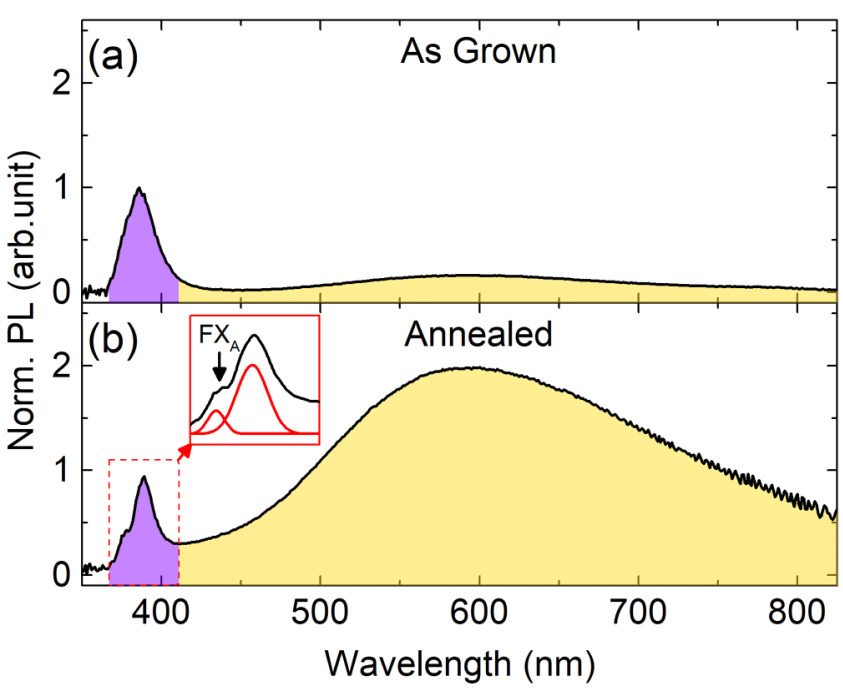

FIG. 4. Room-temperature PL spectra of the (a) as-grown and (b) $900^{\circ} \mathrm{C}$ annealed micropods. 
$3.204 \mathrm{eV}$ band can be attributed to $\mathrm{ZnO}$ near-band-edge (NBE) emission, ${ }^{37}$ while the 3.306 band is consistent with the free exciton $\left(\mathrm{FX}_{\mathrm{A}}\right)$ peak position observed by Guo et al. ${ }^{38}$ The small redshift in the NBE emission of the annealed sample can be attributed to the lattice expansion, creation of Zinc interstitials $\left(\mathrm{Zn}_{\mathrm{i}}\right),{ }^{39}$ or the enhancement of phonon-assisted excitonic emission. It is worth noting that the annealing process does not influence much the overall UV emission intensity. The spectrally integrated UV emission intensities (Fig. 4-violet areas) exhibit an annealed-to-as-grown ratio of $\sim 0.9$, which is the equivalent of a small $10 \%$ decrease.

The excitonic (UV) emission intensity of $\mathrm{ZnO}$ micropods thus stays almost the same before and after annealing in contrast to the drastic increase observed for the defect emission after annealing. Figure 4 shows that both as-grown and annealed $\mathrm{ZnO}$ micropods exhibit a broad emission peak extending from $\sim 410 \mathrm{~nm}$ to $\sim 900 \mathrm{~nm}$ in the visible usually attributed to $\mathrm{ZnO}$ defect emission. ${ }^{40-42}$ Figure 4 reveals that the annealing of $\mathrm{ZnO}$ micropods leads to a strong increase in the $\mathrm{ZnO}$ defect emission. The spectrally integrated visible emission intensities (Fig. 4-yellow areas) exhibit an annealed-to-as-grown ratio of $\sim 16$. This 16 -fold increase in the defect emission is marked by the strong white light emission that can be easily distinguished by the naked eye during the PL measurements of the annealed $\mathrm{ZnO}$ micropods. The UV emission remains almost unchanged; however, there is a drastic increase in the defect emission. This leads to largely differing values for the visible-to-UV ratios between as-grown and annealed samples. The visible-to-UV ratio of $\mathrm{ZnO}$ micropods is strongly increased from $\sim 1.5$ to 24.7 after annealing. Most studies link the increase of the visible-to-UV emission ratio to lower sample quality. However, this assumption does feel quite rudimentary in our case. The annealed $\mathrm{ZnO}$ micropods exhibited FX emission while no FX emission was observed for the as-grown micropods. The FX emission is clear evidence of a higher crystalline quality of the annealed micropods. On the other hand, the enhanced visible emission is an evidence of higher density of defect states. It is important to note that the dimensions of the micropods studied here (1-5 $\mu \mathrm{m}$ diameter, $10-15 \mu \mathrm{m}$ length) gives rise to a surface-to-volume ratio ranging from 1 to 4.6 , which implies a competition between surface and bulk states. This opens the question on the respective role of the defect and bulk states and how each of them affects the final output of the emission spectra. Another interesting point that is put forward in Fig. 4 is the fact that the visible-to-UV emission ratio can be controlled by merely (in the sense of small) annealing the $\mathrm{ZnO}$ micropods. It is important to note that these results for room-temperature $\mathrm{PL}$ measurements were reproduced on several as-grown and $900{ }^{\circ} \mathrm{C}$ annealed micropod samples.

Temperature-dependent PL studies were conducted in order to understand the structural changes and the origin of the drastic spectral changes caused by the annealing of $\mathrm{ZnO}$ micropods. Figure 5 presents the PL spectra at $2 \mathrm{~K}$ for the as-grown (black line) and annealed (red line) $\mathrm{ZnO}$ micropods. Figure 5 reveals a drastic change in the UV emission spectra of the $\mathrm{ZnO}$ micropods after annealing. The PL spectrum of the as-grown sample is dominated by a strong emission band at $3.362 \mathrm{eV}$. This emission band can be attributed to neutral-donor-bound excitons $\left(\mathrm{D}^{0} \mathrm{X}\right){ }^{43}$ Besides the strong $\mathrm{D}^{0} \mathrm{X}$ emission band, the $\mathrm{PL}$ spectrum of the as-grown sample presents a small emission peak at $\sim 3.22 \mathrm{eV}$. The peak at

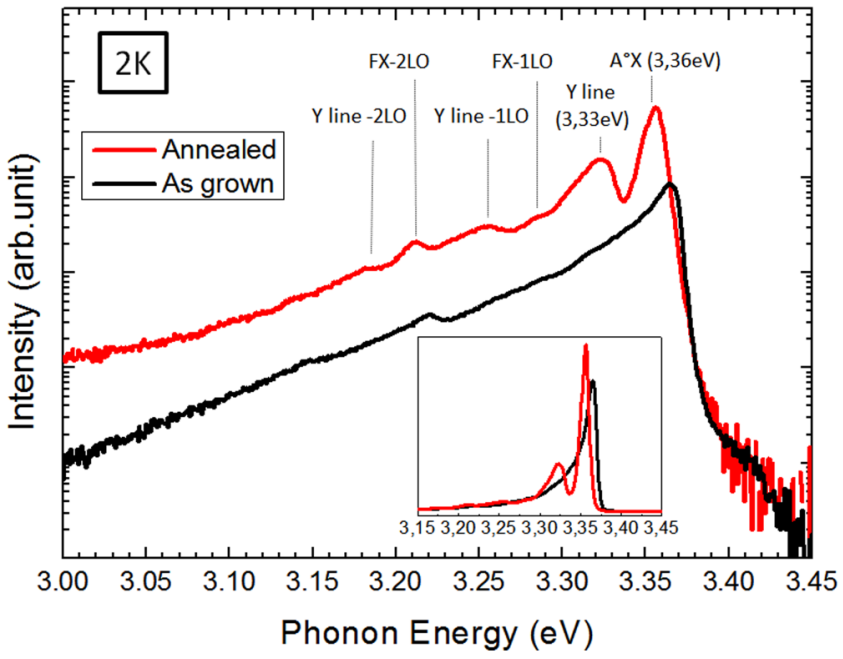

FIG. 5. PL spectra of as-grown and annealed $\mathrm{ZnO}$ microrods at $2 \mathrm{~K}$. The spectra are shown on a logarithmic scale (linear scale plot is shown in the inset) and are vertically displaced for clarity.

$3.22 \mathrm{eV}$ corresponds well with the expected position for the $2 \mathrm{LO}$ phonon replica of the $\mathrm{D}^{0} \mathrm{X}$ emission band $\left(\mathrm{D}^{0} \mathrm{X}-2 \mathrm{LO}\right)$. The $1 \mathrm{LO}$ phonon replica of the $\mathrm{D}^{0} \mathrm{X}$-band $\left(\mathrm{D}^{0} \mathrm{X}-1 \mathrm{LO}\right)$ is expected to appear at $\sim 3.29 \mathrm{eV}$. At $3.29 \mathrm{eV}$, the presence of a small hump corresponds to the $\mathrm{D}^{0} \mathrm{X}-1 \mathrm{LO}$. However, the $\mathrm{D}^{0} \mathrm{X}-1 \mathrm{LO}$ band is extremely weak as it seems to be smeared by the background emissions. On the other hand, the PL spectrum of annealed micropods presents drastically differing spectral features at $2 \mathrm{~K}$. We can mainly observe three different spectral features for the $\mathrm{UV}$ emission of $\mathrm{ZnO}$ micropods after annealing: (1) the redshift in the dominant emission peak and the decrease in the linewidth as seen in the inset of Fig. 5, (2) the presence of a strong emission band at $3.33 \mathrm{eV}$, and (3) the presence of various emission bands at lower energies. As seen in Fig. 5, the main emission band of the $\mathrm{ZnO}$ micropods exhibits a clear redshift. The peak position of the main emission band of the annealed $\mathrm{ZnO}$ micropods is $3.353 \mathrm{eV}$, which represents a redshift of almost $9 \mathrm{meV}$. The energy of the main emission band is too low to be considered as that of neutral-donor-bound exciton but rather fits well the energies expected in the case of a neutral-acceptor-bound exciton $\left(\mathrm{A}^{0} \mathrm{X}\right){ }^{40}$ We note that the as-grown $\mathrm{ZnO}$ micropods presented an $\mathrm{N}-\mathrm{H}$ Raman signature (Fig. 3) but it was missing in the sample annealed at $900^{\circ} \mathrm{C}$ in a nitrogen environment. Similar redshifts, attributed to nitrogen $(\mathrm{N})$ doping of $\mathrm{ZnO}$, have been reported. ${ }^{44-47}$ The $\mathrm{N}$-doping of the $\mathrm{ZnO}$ micropods is evidenced by the disappearance of the N-H Raman signature after annealing (Fig. 3). Nitrogen is a deep level acceptor that lies at $1.3 \mathrm{eV}$ above the $\mathrm{ZnO}$ valence band (VB). In the form of an $\mathrm{N}-\mathrm{H}$ complex, the nitrogen atom is passivated and does not contribute to the doping of $\mathrm{ZnO} .{ }^{44}$ However, when annealed at temperatures above $775^{\circ} \mathrm{C}$, the $\mathrm{N}-\mathrm{H}$ pairs are dissociated, subsequently leading to the $\mathrm{N}$-doping of $\mathrm{ZnO}$. $^{44}$ The transition from a dominant $\mathrm{D}^{0} \mathrm{X}$ 
emission band before annealing to a dominant $\mathrm{A}^{0} \mathrm{X}$ emission band, along with the reduction of the N-H Raman peak, are thus clear proofs of the $\mathrm{N}$-doping of $\mathrm{ZnO}$ micropods. As mentioned, in addition to the redshift of the main emission band, annealed $\mathrm{ZnO}$ micropods present a strong emission peak at $\sim 3.33 \mathrm{eV}$ with a linewidth of about $40 \mathrm{meV}$. The $3.33 \mathrm{eV}$ band has been the subject of various controversial interpretations, which include donor-bound exciton $\left(\mathrm{D}^{0} \mathrm{X}\right),{ }^{48,49}$ acceptor-bound exciton $\left(\mathrm{A}^{0} \mathrm{X}\right),{ }^{50}$ electron-acceptor transitions (e, A), ${ }^{51}$ transitions related to intrinsic point defects, ${ }^{52,53}$ extended structural defects, ${ }^{54,55}$ and two electron satellites (TES). ${ }^{56,57}$ However, the recent consensus is that the $3.33 \mathrm{eV}$ band, often called " $\mathrm{Y}$ " band, is the result of radiative recombinations of excitons bound to extended structural-defect complexes. ${ }^{54,55,57}$ The Y-band is characterized by a relatively low thermal activation energy of $10 \pm 2 \mathrm{meV}$ and a large localization energy of $40 \mathrm{meV} \cdot{ }^{52,53-57}$ Wagner et al. ${ }^{58}$ recently showed that the $3.33 \mathrm{eV}$ band is most likely related to a specific dopant and presents the characteristic of a donor-bound exciton. Cathodoluminescence measurements ${ }^{54,58}$ reveal that the Y-band intensity is stronger in the vicinity of linear cracks, which concludes that the Y-band originates from defect centers such as dislocations and stacking faults. This is further supported by the fact that the Y-band can be observed in $\mathrm{ZnO}$ samples after annealing ${ }^{49,51,59}$ and ion implantation, ${ }^{60}$ which can introduce strong local distortions in the crystal lattice.

The increase in $\mathrm{Y}$ emission in the annealed $\mathrm{ZnO}$ micropods studied here is consistent with the SEM images. SEM images (Fig. 1-inset at the bottom) shows numerous holes appearing on the surface of the $\mathrm{ZnO}$ micropods after annealing. These holes/ cracks are perfect candidates for being Y-band centers. Finally, the annealed $\mathrm{ZnO}$ micropods present various spectral features, which appear at energies below $3.33 \mathrm{eV}$. These are attributed to the $1 \mathrm{LO}$ and $2 \mathrm{LO}$ phonon replicas of the $\mathrm{FX}_{\mathrm{A}}, \mathrm{A}^{0} \mathrm{X}$, and $\mathrm{Y}$ emission bands. The attribution of these spectral features to the LO phonon replicas will be discussed in more detail. However, it is important to note that the reduction in the linewidth of the bound excitonic peak indicates a higher crystal quality of the $\mathrm{ZnO}$ micropods after annealing. ${ }^{6}$

To summarize this section, the annealing process leads to the $\mathrm{N}$-doping of the $\mathrm{ZnO}$ micropods (evident from the $\mathrm{D}^{0} \mathrm{X}$ to $\mathrm{A}^{0} \mathrm{X}$ transition and from Raman spectra), the formation of structural defects at the surface of the micropods (appearance of the Y-band), and an improved crystal quality (evident from the reduction in the PL linewidth). The phonon-exciton coupling is enhanced by annealing, which could be the result of surface defects, improvement of crystal quality, and strain relaxation. ${ }^{61}$ The temperature dependence of the peak energy position is generally the method used for differentiating the nature of various emission bands. Therefore, we have monitored the temperature-dependent PL for both the samples. Hereafter, we will focus on the temperaturedependent spectra of the annealed sample as it presents a few more interesting spectral features.

Figure 6(a) presents the temperature-dependent UV spectra of the annealed $\mathrm{ZnO}$ micropods for temperatures extending from $2 \mathrm{~K}$ to $300 \mathrm{~K}$. The solid bands in Fig. 6(a) are a guide to the eyes for the different peak positions in each spectrum. Figure 6(b) shows the evolution of the various peak energies as a function of temperature. The solid lines in Fig. 6(b) represent the expected energies for the $1 \mathrm{LO}$ and $2 \mathrm{LO}$ phonon replicas determined from the extracted experimental values of the zero phonon lines. The top and bottom solid olive colored lines in Fig. 6(b) represent the estimated energies for the $1 \mathrm{LO}$ phonon replica determined by for
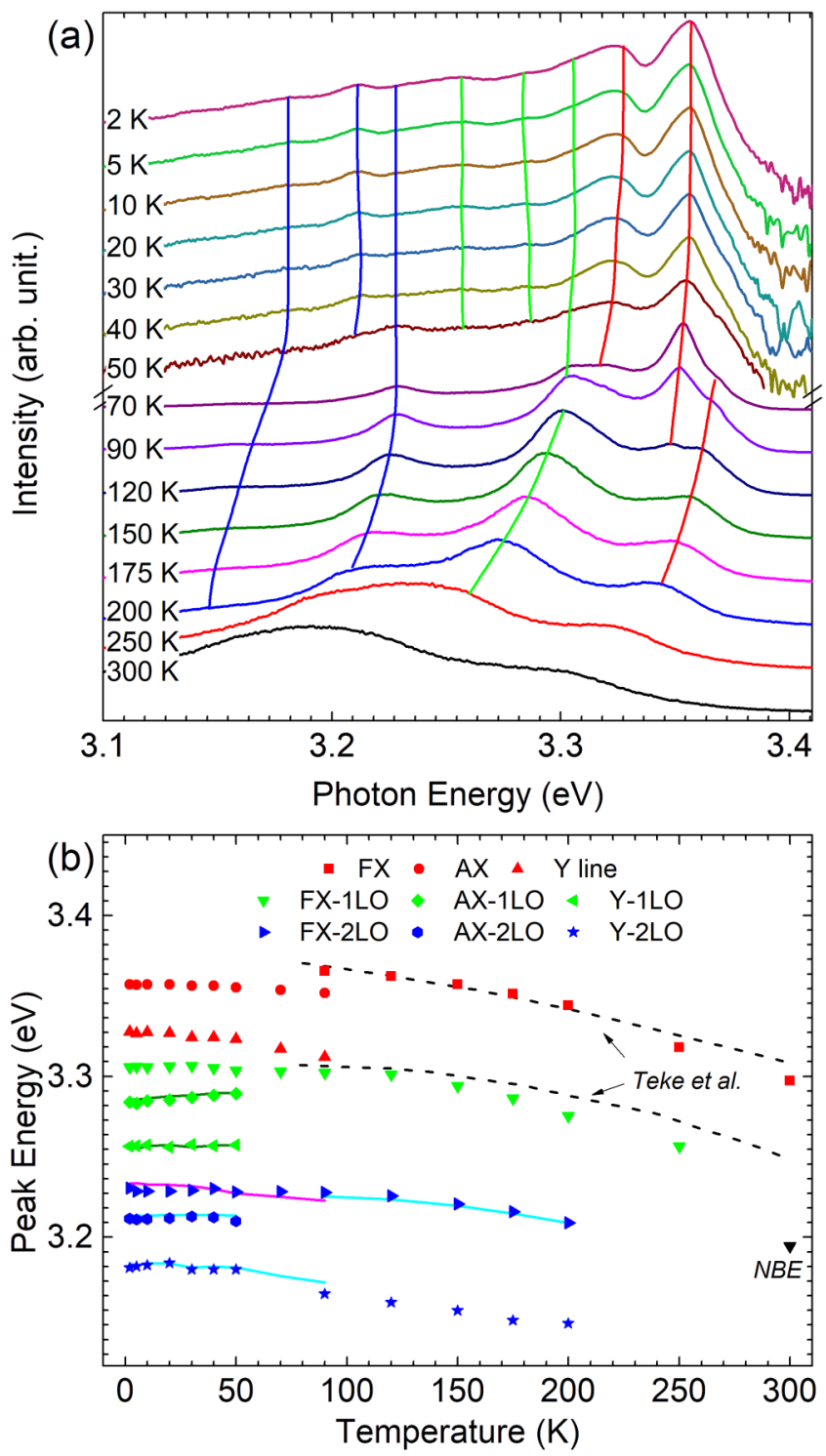

FIG. 6. (a) Evolution of PL spectra as a function of temperature. The spectra recorded at temperatures varying between 2 and $70 \mathrm{~K}$ are shown in a logarithmic scale. PL spectra from $90 \mathrm{~K}$ to $300 \mathrm{~K}$ are plotted in a linear scale. All the spectra are vertically displaced for clarity. Different colors represent the $\mathrm{PL}$ recorded at different temperatures: black $(300 \mathrm{~K})$, red $(250 \mathrm{~K})$, blue $(200 \mathrm{~K})$, fuschia pink $(175 \mathrm{~K})$, tree green $(150 \mathrm{~K})$, dark blue $(120 \mathrm{~K})$, violet $(90 \mathrm{~K})$, magenta $(70 \mathrm{~K})$, maroon $(50 \mathrm{~K})$, olive green $(40 \mathrm{~K})$, navy blue $(30 \mathrm{~K})$, pacific blue $(20 \mathrm{~K})$, light brown $(10 \mathrm{~K})$, light green $(5 \mathrm{~K})$, and pink $(2 \mathrm{~K})$. (b) Peak positions of the temperature-dependent PL spectra for FX, AX, Y-line, FX-1LO, AX-1LO, Y-1LO, FX-2LO, AX-2LO, and Y-2LO peaks. 
the $\mathrm{A}^{0} \mathrm{X}$ and $\mathrm{Y}$, respectively,

$$
E_{\mathrm{XX}-1 \mathrm{LO}}=E_{\mathrm{XX}}-\hbar \omega_{\mathrm{LO}}+1.5 k_{B} T \text {. }
$$

The XX symbol indicates that it can be replaced for any emission lines. The top, middle, and bottom solid cyan lines in Fig. 6(b) represent the estimated energies for the $2 \mathrm{LO}$ phonon replicas determined by

$$
E_{\mathrm{XX}-2 \mathrm{LO}}=E_{\mathrm{XX}}-2 \hbar \omega_{\mathrm{LO}}+0.5 k_{B} T
$$

for the $\mathrm{FX}_{\mathrm{A}}, \mathrm{A}^{0} \mathrm{X}$, and $\mathrm{Y}$, respectively. Figures 6(a) and 6(b) use the following color code: red for the zero phonon lines, green for the $1 \mathrm{LO}$ phonon replicas, and blue for the $2 \mathrm{LO}$ phonon replicas.

Figure 6(a) shows that as the temperature is increased, the $\mathrm{A}^{0} \mathrm{X}$ and $\mathrm{Y}$-band gradually redshifts and it quenches. Between $70 \mathrm{~K}$ and $90 \mathrm{~K}$, many interesting changes occur in the PL spectrum.

First, we observe an increase in the $\mathrm{FX}_{\mathrm{A}}$ contribution to the detriment of the $\mathrm{A}^{0} \mathrm{X}$ one. At $70 \mathrm{~K}$ and above, the $\mathrm{FX}_{\mathrm{A}}$ band can be easily distinguished in the PL spectra. The increased $\mathrm{FX}_{\mathrm{A}}$ contribution is due to the thermally activated detrapping of the acceptorbound exciton. For the annealed $\mathrm{ZnO}$ micropods, the $\mathrm{FX}_{\mathrm{A}}$ band persists even at room temperature (i.e., $300 \mathrm{~K}$ ). This is also observed in Figs. 4(b) and 6(a). It is important to note that the $\mathrm{FX}_{\mathrm{A}}$ band was absent in all the temperature-dependent spectra of the as-grown sample. Second, the PL spectra exhibit less diverse spectral features as the different peaks thermally broaden and merge with increasing temperatures. Below $70 \mathrm{~K}$, we distinguish eight emission bands.

The peak energy of these bands vs temperature is plotted in Fig. 6(b). The two dominant emission bands at higher energies are assigned to the $\mathrm{A}^{0} \mathrm{X}$ and $\mathrm{Y}$-band, respectively, as discussed before. Meanwhile, the six weaker emission bands at lower energies can be attributed to the $1 \mathrm{LO}$ replicas and $2 \mathrm{LO}$ replicas of the $\mathrm{FX}_{\mathrm{A}}$, $\mathrm{A}^{0} \mathrm{X}$, and Y-band.

The attribution of these bands is made via the energy position of these bands. As shown in Fig. 6(b), the energy positions of $3.285 \mathrm{eV}$ (diamonds), $3.257 \mathrm{eV}$ (left-facing triangles), $3.211 \mathrm{eV}$ (hexagons), and $3.181 \mathrm{eV}$ (stars) bands are in good agreement with the predicted energies (solid olive and cyan lines) for the $\mathrm{A}^{0} \mathrm{X}-1 \mathrm{LO}$, $\mathrm{Y}-1 \mathrm{LO}, \mathrm{A}^{0} \mathrm{X}-2 \mathrm{LO}$, and Y-2LO, respectively, which justifies the attribution of these bands to the $1 \mathrm{LO}$ and $2 \mathrm{LO}$ replicas of $\mathrm{A}^{0} \mathrm{X}$ and $\mathrm{Y}$-band. Meanwhile, the $3.306 \mathrm{eV}$ (triangles facing-down) and $3.23 \mathrm{eV}$ (triangles facing right side) bands are attributed to the $\mathrm{FX}_{\mathrm{A}}, 1 \mathrm{LO}$, and $2 \mathrm{LO}$ phonon replica. At temperatures lower than $70 \mathrm{~K}$, the $3.306 \mathrm{eV}$ band (FX-1LO) is observed as a small bump at the low-energy shoulder of the Y-band. The $\mathrm{FX}_{\mathrm{A}}$ contribution is not significant below $70 \mathrm{~K}$ and thus expected energies for the $\mathrm{FX}_{\mathrm{A}}, 1 \mathrm{LO}$, and $2 \mathrm{LO}$ phonon replicas cannot be directly determined from the $\mathrm{FX}_{\mathrm{A}}$.

The attribution of the $1 \mathrm{LO}$ and $2 \mathrm{LO}$ phonon replicas of $\mathrm{FX}_{\mathrm{A}}$ is done differently than those for $\mathrm{A}^{0} \mathrm{X}$ and $\mathrm{Y}$-band. The solid magenta line in Fig. 6(b) represents the expected energies for the 2LO replica determined from the energies of the $1 \mathrm{LO}$ replica $(3.306 \mathrm{eV}$ band) using the relation.

The $3.23 \mathrm{eV}$ band shows a good agreement with the solid magenta line. It is also worth noting that the $3.23 \mathrm{eV}$ band is not in good agreement with the expected energies for a $1 \mathrm{LO}$ phonon replica of the $3.306 \mathrm{eV}$,

$$
E_{\mathrm{XX}-2 \mathrm{LO}}=E_{\mathrm{XX}-1 \mathrm{LO}}-\hbar \omega_{\mathrm{LO}}-k_{B} T .
$$

Thus, we conclude that the $3.23 \mathrm{eV}$ band is not the $1 \mathrm{LO}$ replica of the $3.305 \mathrm{eV}$ band but the $3.306 \mathrm{eV}$ band and $3.23 \mathrm{eV}$ band are rather the $1 \mathrm{LO}$ and $2 \mathrm{LO}$ phonon replicas of another emission band. At $2 \mathrm{~K}$, the energy of the zero phonon line of the $3.306 \mathrm{eV}$ and $3.23 \mathrm{eV}$ phonon replicas is estimated to be $3.376 \mathrm{eV}$, roughly the expected energy for the $\mathrm{FX}_{\mathrm{A}}{ }^{40}$ Thus, the $3.306 \mathrm{eV}$ and $3.23 \mathrm{eV}$ bands are $1 \mathrm{LO}$ and $2 \mathrm{LO}$ phonon replicas of $\mathrm{FX}_{\mathrm{A}}$. The FX-1LO replica is last observed at $90 \mathrm{~K}$. At $90 \mathrm{~K}$, the FX-1LO and the Y-band merge and start to dominate the PL spectrum, as their peak energies cross over [Fig. 6(b) triangles facing upward and downward]. The two dashed black lines in Fig. 6(b) represent the peak position of the free exciton and 1LO phonon replica of the free exciton reported by Teke et al. ${ }^{62}$ The dashed lines serve to show that above $90 \mathrm{~K}$, with the thermal broadening and roughly similar energies, we cannot talk about a sole Y-band or FX-1LO band but we rather have a joint Y/FX-1LO band. At $150 \mathrm{~K}$, the X eventually merges with the $\mathrm{FX}_{\mathrm{A}}$ and the $\mathrm{PL}$ spectrum gets composed of four emission bands, the $\mathrm{FX}_{\mathrm{A}}$ and Y/FX-1LO bands and their 2LO phonon replica at $3.221 \mathrm{eV}$ and $3.154 \mathrm{eV}$, respectively. The Y-2LO band is very weak and cannot be easily distinguished in Fig. 6(a). As shown in Fig. 6(b), the $3.221 \mathrm{eV}$ (triangles facing to the right) and $3.154 \mathrm{eV}$ (stars) bands present a good agreement with expected energies (solid cyan lines) for the $2 \mathrm{LO}$ phonon replicas of $\mathrm{FX}_{\mathrm{A}}$ and Y-band, justifying their attribution. It is important to note that the existence of FX-2LO certainly asserts the existence of FX-1LO. Yet, due to thermal broadening, the FX-1LO band could not be distinguished from the Y-band, as mentioned before. It is also important to note that the peak position of $3.221 \mathrm{eV}$ band (i.e., FX-2LO) above $90 \mathrm{~K}$ are continuous with the peak position of the $3.23 \mathrm{eV}$ band below $90 \mathrm{~K}$, which again justifies the assignment of the $3.23 \mathrm{eV}$ band to the FX-2LO. At $90 \mathrm{~K}$, the Y-band/FX-1LO peak is around $\sim 3.31 \mathrm{eV}$. The $3.31 \mathrm{eV}$ emission band at low temperature has been the subject of a long-standing debate. Several interpretations about this peak have been discussed in the literature. The two main hypotheses that are generally evoked to explain it are, namely, the $1 \mathrm{LO}$ phonon replica of the free exciton and the A-band. Thus, one might question if the peak might correspond to the A-band. Tainoff et al. recently presented a systematic and comprehensive study on the origin of the $3.31 \mathrm{eV}$ band. ${ }^{63}$ In our case, $3.31 \mathrm{eV}$ band contribution is very weak below $70 \mathrm{~K}$ and significantly increases above $70 \mathrm{~K}$. This is a behavior consistent with that observed by Tainoff et al. for the 1LO phonon of the free exciton. It is also important to note that the increase of the LO-phonon-exciton with increasing temperatures has also been observed in various studies where the phonon-assisted FX recombination even dominates the FX and NBE emissions, ${ }^{64,65}$ due to enhanced electron-phonon interaction. ${ }^{66}$ Moreover, the evolution of the energy difference of the FX and the $3.31 \mathrm{eV}$ band in our case does not show the expected temperature dependences for the A-band (Fig. S1 in the supplementary material), as proposed by Tainoff et al. It is important to note that the energy difference of the 3.31 band exhibits a linear increase with an increase in temperature. Due to these observations, we prioritize the $3.31 \mathrm{eV}$ band to be the FX-1LO. 
To understand the mechanisms behind the colossal (16-fold) increase in defect emission after annealing, we investigate the temperature-dependent PL spectra of annealed $\mathrm{ZnO}$ micropods in the visible spectrum. Figure 7 (a) presents the temperature-dependent visible spectra of the annealed $\mathrm{ZnO}$ micropods for temperatures extending from $2 \mathrm{~K}$ to $300 \mathrm{~K}$. As seen in Fig. 7(a), the intensity of the defect emission generally decreases with increasing temperature. As temperature increases, the position of the maximum intensity also significantly blue-shifts, going from $\sim 1.8 \mathrm{eV}$ at $2 \mathrm{~K}$ to $\sim 2.1 \mathrm{eV}$ at $300 \mathrm{~K}$. However, looking more closely, we remark a rather interesting behavior. While the intensity of the low-energy shoulder $(\sim 1.7 \mathrm{eV})$ of the defect emission decreases with increasing temperatures, the intensity of the high-energy shoulder $(\sim 2.3 \mathrm{eV})$ of the defect emission presents an increase over a specific temperature range. This increase in the intensity is rather intriguing and raises questions, requiring further analysis of the defect emission. The defect emission can be fitted using two Gaussian peaks at $\sim 1.74 \mathrm{eV}$ (red emission) and $\sim 2.05 \mathrm{eV}$ (orange emission), respectively. FWHM is $0.46 \mathrm{eV}$ for the orange and $0.4 \mathrm{eV}$ for the red emission. It is important to note that the $1.74 \mathrm{eV}$ band is not observed in as-grown $\mathrm{ZnO}$ micropods (results not presented here). The $1.74 \mathrm{eV}$ band is formed in $\mathrm{ZnO}$ micropods after annealing. This observation is consistent with the $\mathrm{N}$-doping of $\mathrm{ZnO}$ micropods discussed previously. $\mathrm{N}$-doped $\mathrm{ZnO}$ usually presents a broad PL emission band peaking at $1.7 \mathrm{eV}$, which agrees with the deep-acceptor model of the nitrogen defect. ${ }^{44}$ The $1.74 \mathrm{eV}$ band is, thus, another sign of the $\mathrm{N}$-doping of annealed $\mathrm{ZnO}$ micropods. The evolution of the spectrally integrated intensities (i.e., areas) of the red (squares) and orange (circles) emissions is plotted as a function of temperature inverse in Fig. 7(b). Figure 7(b) shows that the intensity of the red emission decreases exponentially as temperature is increased. The spectrally integrated intensity $(\eta)$ of the red emission is fitted using ${ }^{24}$ the following equation:

$$
\eta(T)=\frac{P_{0}}{1+P_{1} e^{-E_{1} / k_{B} T}},
$$

where $P_{0}$ and $P_{1}$ are fitting parameters, $E_{1}$ is the activation energy, and $k_{B}$ is the Boltzmann constant. The solid red line in Fig. 7(b) presents the curve fitting for the red emission.

The determined activation energy from the fit is about $\sim 14.4 \mathrm{meV}$. More importantly, the intensity of the orange emission exhibits a negative thermal quenching (NTQ). With increasing temperatures, the intensity of the orange emission is first unaffected, presenting only a minor decrease in intensity. At $90 \mathrm{~K}$, the intensity of the orange emission presents an inflection point and begins to increase, exhibiting a negative thermal quenching between $90 \mathrm{~K}$ and $200 \mathrm{~K}$, before eventually decreasing very fast at temperatures above $200 \mathrm{~K}$. NTQ occurs due to the fact that the localized excitons get thermally excited into less localized or free states. These excitons can, thus, reach nonradiative or deep recombination centers due to an increased diffusion length. The spectrally integrated intensity of the orange emission can be fitted using Shibata's equation, ${ }^{67,68}$

$$
\eta(T)=\frac{1+\sum_{q=1}^{n} D_{q} e^{-E_{q}^{\prime} / k_{B} T}}{1+\sum_{i=1}^{m} P_{q} e^{-E_{i} / k_{B} T}},
$$
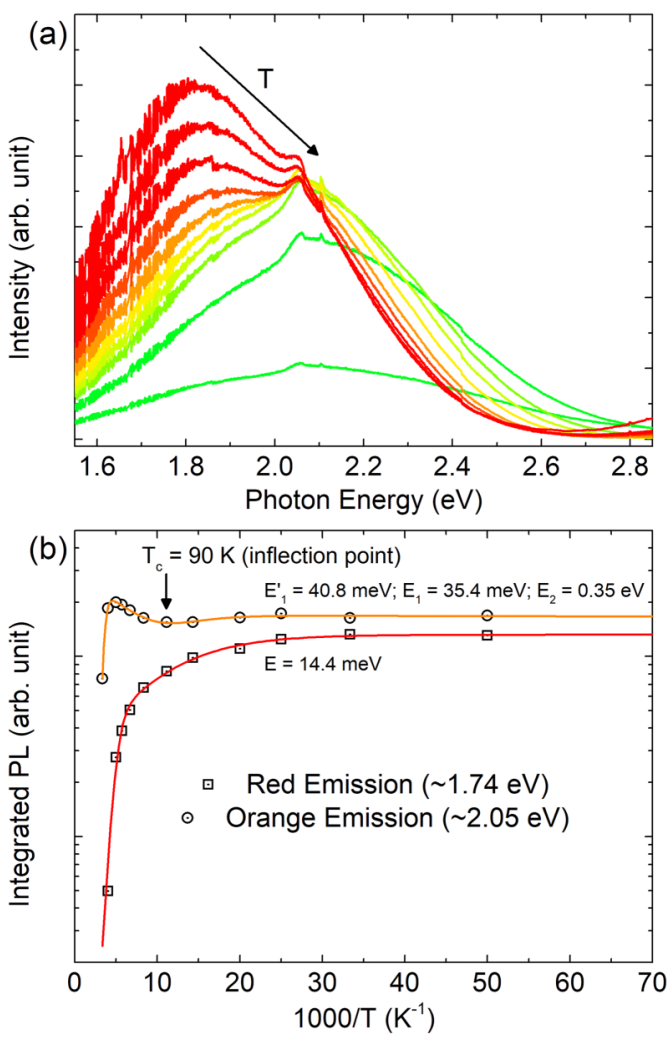

(c) $10 \mathrm{~K}$

(d) $200 \mathrm{~K}$

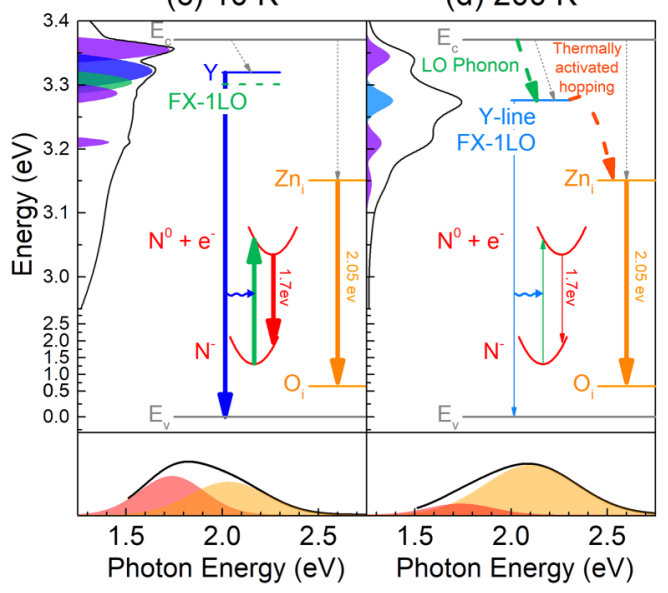

FIG. 7. Defect emission: (a) temperature dependence from $70 \mathrm{~K}$ to $200 \mathrm{~K}$. (b) Red and orange lines represent integrated emission as a function of the inverse of the temperature, evidencing thermal quenching, (c) and (d) proposed mechanism at $10 \mathrm{~K}$ and $200 \mathrm{~K}$, respectively.

where $D_{q}$ and $P_{q}$ are fitting parameters. $E_{q}^{\prime}$ are the activation energies of the processes that increase the intensity with increasing temperature.

The solid orange line in Fig. 7(b) presents the curve fitting conducted for the orange emission. After the curve fitting, we obtain the 
following activation energies $E_{1}^{\prime} \approx 40.8 \mathrm{meV}, E_{1}=35.4 \mathrm{meV}$, and $E_{2}=0.35 \mathrm{eV}$, respectively. The activation energies determined for the red and orange emission are actually quite interesting, more specifically, the activation energy of $\sim 14 \pm 3 \mathrm{meV}$ for the thermal quenching of the red emission and the activation energy of $\sim 40 \mathrm{meV}$ for the NTQ of the orange emission. These energies coincide perfectly with the thermal activation energy $(10 \pm 2 \mathrm{meV})$ and localization energy ( $40 \mathrm{meV}$ ) of the Y-band. It is important to remember that the defect emissions drastically increase after annealing. The main difference between the low-temperature UV emission of as-grown and annealed $\mathrm{ZnO}$ micropods is the presence of the Y-band. These observations raise questions on the relation between the Y-band and the orange and red emissions. It is also important to note that the inflection point for the spectrally integrated intensity of the orange emission is at $90 \mathrm{~K}$ [indicated by an arrow in Fig. 7(b)]. The Y-band and FX-1LO emissions cross over at this same temperature. At $90 \mathrm{~K}$, the energy of the FX-1LO varies from below the Y-band energy to slightly above the Y-band. This suggests that the LO phonons play a role in the orange emission. As mentioned before, the red emission results from nitrogen $\left(\mathrm{N}^{-}\right)$ions. The $\mathrm{N}^{-}$ions have an absorption onset at $\sim 2.4 \mathrm{eV}$ and a broad PL emission at $1.7 \mathrm{eV}$ due to a Franck-Condon shift of $0.7 \mathrm{eV}$. When excited at $2.4 \mathrm{eV}$, an electron from the $\mathrm{N}^{-}$is excited, transitioning the charged nitrogen from an $\mathrm{N}^{-}$state to dissociated neutral nitrogen and an electron state $\left(\mathrm{N}^{0}+\mathrm{e}\right)$. Nitrogen afterward recaptures the electron and light is emitted at $1.7 \mathrm{eV}$. The $\mathrm{N}^{0}+\mathrm{e}$ state is an excited state and thus does not exist before the excitation of the $\mathrm{N}^{-}$ions. Moreover, the energy of the $\mathrm{N}^{-}$state lies at $1.3 \mathrm{eV}$ above the $\mathrm{ZnO}$ valence band (VB). With an absorption onset of $2.4 \mathrm{eV}$, this puts the excited $\mathrm{N}^{0}+\mathrm{e}$ state at $3.7 \mathrm{eV}, \sim 0.3 \mathrm{eV}$ above the $\mathrm{ZnO}$ conduction band (CB). Thus, it is almost unlikely that the transition from $\mathrm{N}^{-}$to $\mathrm{N}^{0}+\mathrm{e}$ would be the result of a nonradiative process. The $\mathrm{N}^{-}$to $\mathrm{N}^{0}+\mathrm{e}$ transition most likely results from a radiative transfer, i.e., excitation by photons. PLE measurements (results not presented here) reveal a radiative excitation channel of the red emission between $372 \mathrm{~nm}(\sim 3.33 \mathrm{eV})$ and $380 \mathrm{~nm}(3.26 \mathrm{eV})$, corresponding to the energy range of the Y-band.

The red emission, thus, exhibits a strong radiative coupling with the Y-band, which explains why the red emission shows almost the same activation energy as the Y-band. This strong coupling could also be the result of the high refractive index of $\mathrm{ZnO}$ $(2.1$ at $3.33 \mathrm{eV})$, which can lead to a strong confinement of light within $\mathrm{ZnO}$ micro- and nanostructures. ${ }^{69,70}$ Moreover, the radiative nature of this energy transfer also explains why it is not dependent on the strong localization energy of the Y-band. The orange emission, on the other hand, presents a blue shift with increasing temperature. This behavior is similar to that observed by $\mathrm{He}$ et al., ${ }^{71}$ suggesting a DAP-like transition involving a shallow donor and a deep acceptor. He et al. showed that the orange emission is unlikely from the surface but rather from the bulk.

The orange emission is usually attributed to an electron transition from zinc interstitial defect level $\left(\mathrm{Zn}_{\mathrm{i}}\right),{ }^{71-73}$ at $0.22 \mathrm{eV}$ below the $\mathrm{ZnO} \mathrm{CB}$, to oxygen interstitial defect level $\left(\mathrm{O}_{\mathrm{i}}\right)$, at $1.09 \mathrm{eV}$ above the $\mathrm{ZnO} \mathrm{VB}^{72,73}$ The NTQ of the orange emission has an activation energy of $\sim 40 \mathrm{meV}$. The NTQ most likely indicates recapture of thermalized carriers/excitons by the $\mathrm{Zn}_{\mathrm{i}}$ centers responsible for the orange emission. Since the activation energy of the NTQ is similar to that of the localization energy of the Y-band, the thermalized excitons are that of the Y-band. As the Y-band carriers get delocalized, they are able to diffuse over a wider area which increases their chances of being captured by $\mathrm{Zn}_{\mathrm{i}}$ defects. Figures 7 (c) and 7(b) present an energy level diagram summarizing the various mechanisms to explain the thermal quenching of red emission and negative thermal quenching of the orange emission. All energy levels are presented to scale except for the $\mathrm{N}^{0}+\mathrm{e}$ level. The $\mathrm{N}^{-}$ions should transit to a $\mathrm{N}^{0}+\mathrm{e}$ energy level above the $\mathrm{ZnO}$ $\mathrm{CB}$. However, for clarity, the $\mathrm{N}^{0}+\mathrm{e}$ level is entirely presented under the $\mathrm{ZnO} \mathrm{CB}$. At $10 \mathrm{~K}$ [Fig. 7 (c)], the Y-band carrier decays, emitting light at $3.33 \mathrm{eV}$. The $\mathrm{Y}$-band emission excites the $\mathrm{N}^{-}$ions to $\mathrm{N}^{0}+\mathrm{e}$ state, which, after relaxing back to the $\mathrm{N}^{-}$state, emits light at $1.7 \mathrm{eV}$. On the other hand, electrons from the $\mathrm{ZnO}$ conduction band decay to the $\mathrm{Zn}_{\mathrm{i}}$ level via nonradiative channels, eventually emitting light at $2.05 \mathrm{eV}$. At $200 \mathrm{~K}$ [Fig. 7 (d)], electrons from the $\mathrm{ZnO}$ conduction band are more efficiently captured by the Y-band via LO-phonon-assisted decay, which is manifested by the higher Y-band intensity as compared to the free exciton intensity [Fig. 6(a)]. This leads to a high population of the Y-band. However, at $200 \mathrm{~K}$, the Y-band carriers are thermalized the most, due to their low activation energy. Only few Y-band carriers actively recombine, giving way to light being emitted at $\sim 3.3 \mathrm{eV}$. The Y-band emission is much weaker at $200 \mathrm{~K}$ as compared to $10 \mathrm{~K}$. The $\mathrm{N}^{-}$ions are, thus, very weakly excited as manifested by the weak red emission [Fig. 7(d)]. However, at $200 \mathrm{~K}$, the thermalized Y-band carriers are free to move around and are eventually captured by $\mathrm{Zn}_{\mathrm{i}}$ defect centers. The thermally activated hopping of Y-band carriers leads to an additional nonradiative channel. This channel can be further enhanced due to the redshift of the Y-band, which brings it close to the $\mathrm{Zn}_{\mathrm{i}}$ level. In addition, this channel also leads to an increase in orange emission as carriers are efficiently captured by $\mathrm{Zn}_{\mathrm{i}}$ centers. The suggested mechanisms in Figs. 7(c) and 7(d) are strongly supported and are in agreement with the various results discussed herein; moreover, they perfectly explain the behavior of the orange and red emissions.

\section{SUMMARY}

We have successfully synthesized well-structured, crystalline $\mathrm{ZnO}$ micropods by using a low temperature based chemical bath deposition technique. These micropods are either bipods, tetrapods, or hexapods in form as observed from SEM images. XRD patterns showed that these micropods have a Wurtzite hexagonal structure and are highly crystalline. Room-temperature PL measurements conducted on these as-grown and annealed samples show a typical near-band-edge UV emission band centered at $3.23 \mathrm{eV}$ and a broad visible emission band at $2.08 \mathrm{eV}$. After thermal annealing, the intensity of UV emission remained almost the same, while the defect emission gets much enhanced, which indicates higher density of defect. An increase in the intensity of the $E_{2}$ high phonon mode in the annealed micropods is an indication that annealed microrods are better crystallized as compared to as-grown micropods. The presence of $\mathrm{O}-\mathrm{H}$ and $\mathrm{N}-\mathrm{H}$ groups in the as-grown sample was observed in Raman measurements, while they were absent after annealing. The linewidth of the $\mathrm{E}_{2}(\mathrm{H})$ mode in the Raman spectrum was observed to decrease after annealing, proving that the crystallinity of the 
sample had further increased after annealing. However, the appearance of the Y-line in the low-temperature PL spectra of the annealed sample suggested the presence of structural and surface defects, which trap a certain amount of photon excited excitons. Through the combined analysis on the evolutions of the excitonic peaks and the defect emission, we conclude that the general crystal quality of micropods has been improved after annealing. However, additional structural and surface defects have also been created in the micropods, which trap thermally activated excitons and consequently enhance the defect emission. Finally, our work suggests that the mechanism of NTQ of the defect emission can be attributed to this trapping effect. The as-grown $\mathrm{ZnO}$ micropods showed the lowest defect emission and the highest UV-to-visible peak emission ratio, which is an interesting aspect for UV random lasing applications. On the other hand, the $900{ }^{\circ} \mathrm{C}$ annealed micropods showed the highest defect emission and the lowest UV-to-visible peak emission ratio, which is an interesting aspect for lighting applications. Most interestingly, the UV-to-visible peak emission ratio could be controlled by annealing the $\mathrm{ZnO}$ micropods.

\section{SUPPLEMENTARY MATERIAL}

In the supplementary material, Fig. S1 represents the energy difference of the 3.31 band that exhibits a linear increase with an increase in temperature. The evolution of the energy difference of the FX and the $3.31 \mathrm{eV}$ band does not show the expected temperature dependences for the A-band.

\section{ACKNOWLEDGMENTS}

This work, through the MATISSE project, has been partially supported by the Champagne-Ardenne Regional Council and the European Social Fund. The authors take this opportunity to thank Dr. Christophe Couteau for early discussions. We also thank the NANOMAT platform for the equipment provided to us for characterization purpose. Dr. Junze Zhou would like to thank the Chinese Scholarship Council for his Ph.D fellowship (No. 201306120067). The authors would like to thank the support of the ANR (French National Agency for Research) through the DECISION Project No. ANR-17-CE9-0014.

There are no conflicts to declare.

\section{REFERENCES}

${ }^{1}$ D. Norton, Y. Heo, M. Ivill, K. Ip, S. Pearton, M. Chisholm, and T. Steiner, Mater. Today 7, 34 (2004).

${ }^{2}$ Z. Wang, J. Phys. Condens. Matter 16, R829 (2004).

${ }^{3}$ W. Park and G.-C. Yi, Adv. Mater. 16, 87 (2004).

${ }^{4}$ R. Könenkamp, R. Word, and C. Schlegel, Appl. Phys. Lett. 85, 6004 (2004).

${ }^{\mathbf{5}}$ M. Willander, O. Nur, Q. Zhao, L. Yang, M. Lorenz, B. Cao et al. Nanotechnology 20, 332001 (2009).

${ }^{6}$ J. Goldberger, D. Sirbuly, M. Law, and P. Yang, J. Phys. Chem. B 109, 9 (2005).

${ }^{7_{H}}$ H. Ng, J. Han, T. Yamada, P. Nguyen, Y. Chen, and M. Meyyappan, Nano Lett. 4, 1247 (2004).

${ }^{8}$ W. Park, J. Kim, G. Yi, and H. Lee, Adv. Mater. 17, 1393 (2015).

${ }^{9}$ H. Huang, S. Mao, H. Feick, H. Yan, Y. Wu, H. Kind, E. Weber, R. Russo, and P. Yang, Science 292, 1897 (2001).

${ }^{10}$ J. Choy, E. Jang, J. Won, J. Chung, D. Jang, and Y. Kim, Adv. Mater. 15, 1911 (2003).
${ }^{11}$ K. Nomenyo, A.-S. Gadallah, S. Kostcheev, D. J. Rogers, and G. Lerondel, Appl. Phys. Lett. 104, 181104 (2014).

12 Z. Fan and J. Lu, Appl. Phys. Lett. 86, 123510 (2005).

${ }^{13}$ Q. Wan, Q. Li, Y. Chen, T. Wang, X. He, J. Li, and C. Lin, Appl. Phys. Lett. 84, 3654 (2004).

${ }^{14}$ R. Aad, V. Simic, L. Le Cunff, L. Rocha, C. Sartel, V. Sallet, A. Lusson, C. Couteau, and G. Lerondel, Nanoscale 5, 9176 (2013).

15. Xu, Q. Pan, and Z. Tian, Sens. Actuators B 66, 277 (2000).

${ }^{16}$ M. Law, L. Greene, J. Johnson, R. Saykally, and P. Yang, Nat. Mater. 4, 455 (2000).

17. Baxter and E. Aydil, Appl. Phys. Lett. 86, 053114 (2005).

${ }^{18}$ C. Levy-Clement, R. Tena-Zaera, M. Ryan, A. Katty, and G. Hodes, Adv. Mater. 17, 1512 (2005)

${ }^{19}$ A.-S. Gadallah, K. Nomenyo, C. Couteau, D. Rogers, and G. Lérondel, Appl. Phys. Lett. 102, 171105 (2013).

${ }^{20}$ R. Aad, C. Couteau, S. Blaize, E. Chastaing, F. Soyer, L. Divay, C. Galindo, P. Le Barny, V. Sallet, C. Sartel, A. Lusson, P. Galtier, L. Rocha, V. Simic, and G. Lérondel, ACS Photonics 1, 246 (2013).

${ }^{21}$ A. Djurišić, X. Chen, Y. Leung, and A. Ng, J. Mater. Chem. 22, 6526 (2012).

${ }^{22}$ J. Elias, C. Clément, M. Bechelany, J. Michler, G. Wang, Z. Wang, and L. Philippe, Adv. Mater. 22, 1607 (2010).

${ }^{23}$ A. Gokarna, R. Parize, H. Kadiri, K. Nomenyo, G. Patriarche, P. Miska, and G. Lerondel, RSC Adv. 4, 47234 (2014).

${ }^{\mathbf{2 4}}$ L. Vaysierres, Adv. Mater. 15, 464 (2003).

${ }^{25}$ Q. Ahsanulhaq, S. H. Kim, and Y. B. Hahn, J. Alloys Compd. 484, 17 (2009).

${ }^{26}$ Q. Ahsanulhaq, J. Kim, N. Reddy, and Y. Hahn, J. Ind. Eng. Chem. 14, 578 (2008).

${ }^{27}$ B. Wang, E. Shi, and W. Zhong, Cryst. Res. Technol. 32, 659 (1997).

${ }^{28}$ B. Wang, E. Shi, and W. Zhong, Cryst. Res. Technol. 33, 937 (1998).<937:: AID-CRAT937>3.0.CO;2-8

${ }^{29}$ P. Borade, K. Joshi, A. Gokarna, G. Lerondel, and S. Jejurikar, Nanotechnology 27, 025602 (2016).

${ }^{30}$ P. Borade, K. Joshi, A. Gokarna, G. Lerondel, P. Walke, D. Late, and S. Jejurikar, Mater. Chem. Phys. 169, 1522016 (2016).

${ }^{31}$ B. Cao and W. Cai, J. Phys. Chem. C 112, 680 (2008).

${ }^{32}$ R. Majitha, J. Speich, and K. E. Meissner, Materials 6, 2497 (2013).

${ }^{33}$ K. Govender, D. S. Boyle, P. B. Kenway, and P. O’Brien, J. Mater. Chem. 14, 2575 (2004).

${ }^{34}$ M. A. Vergés, A. Mifsud, and C. J. Serna, J. Chem. Soc. Faraday Trans. 86, 959 (1990).

${ }^{35}$ A. P. A. Oliveira, J.-F. Hochepied, F. Grillon, and M.-H. Berger, Chem. Mater. 15, 3202 (2003).

${ }^{36}$ Y. J. Xing, Z. H. Xi, Z. Q. Xue, X. D. Zhang, J. H. Song, R. M. Wang, J. Xu, Y. Song, S. L. Zhang, and D. P. Yu, Appl. Phys. Lett. 83, 1689 (2003).

${ }^{37}$ R. Aad, L. Divay, A. Bruyant, S. Blaize, C. Couteau, D. Rogers, and G. Lerondel, J. Appl. Phys. 112, 063112 (2012).

${ }^{38}$ X. Guo, C. Tripp, C. Chen, Y. Wang, S. Yin, and W. Qin, CrystEngComm 18, 3130 (2016).

${ }^{39}$ M. Jiang, M. Jiang, D. Wang, B. Zou, Z. Q. Chen, A. Kawasuso, and T. Sekiguchi, Phys. Status Solidi A 209, 2126 (2012).

${ }^{40}$ Ü. Özgür, Ya. I. Alivov, C. Liu, A. Teke, M. Reshchikov, S. Doğan, V. Avrutin, S. Cho, and H. Morkoç, J. Appl. Phys. 98, 041301 (2005).

${ }^{41}$ A. Djurisić and Y. H. Leung, Small 2(8-9), 944 (2006).

${ }^{42}$ E. Erdem, J. Alloys and Compounds 605, 34 (2014).

${ }^{43}$ D. C. Look, D. C. Reynolds, J. R. Sizelove, R. L. Jones, C. Litton, G. Cantwell, and W. C. Harsch, Solid State Commun. 105, 399 (1998).

${ }^{44}$ M. C. Tarun, M. Z. Iqbal, and M. D. McCluskey, AIP Adv. 1, 22105 (2011).

${ }^{45}$ A. Alkauskas, M. D. McCluskey, and C. G. Van de Walle, J. Appl. Phys. 119, 181101 (2016).

${ }^{46}$ L. Wang, B. Lin, L. Zhou, Y. X. Shang, G. N. Panin, and D. Fu, Mater. Lett. 85, 171 (2012).

${ }^{47}$ E. Guziewicz, E. Przezdziecka, D. Snigurenko, D. Jarosz, B. S. Witkowski, P. Dluzewski, and W. Paszkowicz, ACS Appl. Mater. Interfaces 9, 26143 (2017). 
${ }^{48}$ A. Schildknecht, R. Sauer, and K. Thonke, Physica B 340, 205 (2003).

${ }^{49} \mathrm{~K}$. Johnston, M. O. Henry, D. McCabe, E. McGlynn, M. Dietrich, E. Alves, and M. Xia, Phys. Rev. B 73, 165212 (2006).

${ }^{\mathbf{5 0}}$ H. Kato, M. Sano, K. Miyamoto, and T. Yao, Jpn. J. Appl. Phys. 42, L1002 (2003).

${ }^{51}$ B. Wang, M. J. Callahan, L. O. Bouthillette, C. Xu, and M. J. Suscavage, J. Cryst. Growth 287, 381 (2006).

${ }^{52}$ H. Shibata, M. Watanabe, M. Sakai, K. Oka, P. Fons, K. Iwata, A. Yamada, K. Matsubara, K. Sakurai, H. Tampo, K. Nakahara, and S. Niki, Phys. Status Solidi C 1, 872 (2004).

${ }^{53} \mathrm{H}$. Tampo, H. Shibata, P. Fons, A. Yamada, K. Matsubara, K. Iwata, K. Tamura, H. Takasu, and S. Niki, J. Cryst. Growth 278, 268 (2005).

${ }^{54}$ H. Alves, D. Pfisterer, A. Zeuner, T. Riemann, J. Christen, D. M. Hofmann, and B. K. Meyer, Opt. Mater. 23, 33 (2003).

${ }^{55}$ B. K. Meyer, H. Alves, D. M. Hofmann, W. Kriegseis, D. Forster, F. Bertram,

J. Christen, A. Hoffmann, M. Straßburg, M. Dworzak, U. Haboeck, and A. V. Rodina, Phys. Status Solidi B 241, 231 (2004).

${ }^{\mathbf{5 6}}$ T. Hirai, Y. Harada, S. Hashimoto, N. Ohno, and T. Itoh, J. Lumin. 113, 115 (2005).

${ }^{57}$ S. F. Chichibu, T. Onuma, M. Kubota, A. Uedono, T. Sota, A. Tsukazaki, A. Ohtomo, and M. Kawasaki, J. Appl. Phys. 99, 93505 (2006).

${ }^{58}$ M. R. Wagner, G. Callsen, J. S. Reparaz, J.-H. Schulze, R. Kirste, M. Cobet, I. A. Ostapenko, S. Rodt, C. Nenstiel, M. Kaiser, A. Hoffmann, A. V. Rodina, M. R. Phillips, S. Lautenschläger, S. Eisermann, and B. K. Meyer, Phys. Rev. B 84, 035313 (2011)
${ }^{59}$ J. Fallert, R. J. B. Dietz, M. Hauser, F. Stelzl, C. Klingshirn, and H. Kalt, J. Lumin. 129, 1685 (2009).

${ }^{60}$ R. Kirste, Y. Aksu, M. R. Wagner, S. Khachadorian, S. Jana, M. Driess, C. Thomsen, and A. Hoffmann, ChemPhysChem 12, 1189 (2011).

${ }^{61}$ W.-K. Hong, G. Jo, M. Choe, T. Lee, J. I. Sohn, and M. E. Welland, Appl. Phys. Lett. 94, 043103 (2009).

${ }^{62}$ A. Teke, Ü. Özgür, S. Doğan, X. Gu, H. Morkoç, B. Nemeth, J. Nause, and H. O. Everitt, Phys. Rev. B 70, 195207 (2004).

${ }^{63}$ D. Tainoff, B. Masenelli, P. Mélinon, A. Belsky, G. Ledoux, D. Amans, C. Dujardin, N. Fedorov, and P. Martin, Phys. Rev. B 81, 115304 (2010).

${ }^{64}$ C. Ton-That, L. L. C. Lem, M. R. Phillips, F. Reisdorffer, J. Mevellec, T.-P. Nguyen, C. Nenstiel, and A. Hoffmann, New J. Phys. 16, 83040 (2014).

${ }^{65}$ W. Shan, W. Walukiewicz, J. W. Ager, K. M. Yu, H. B. Yuan, H. P. Xin, G. Cantwell, and J. J. Song, Appl. Phys. Lett. 86, 191911 (2005).

${ }^{66}$ T. Makino, C. H. Chia, N. T. Tuan, Y. Segawa, M. Kawasaki, A. Ohtomo, K. Tamura, and H. Koinuma, Appl. Phys. Lett. 76, 3549 (2000).

${ }^{67}$ M. Hauser, A. Hepting, R. Hauschild, H. Zhou, J. Fallert, H. Kalt, and C. Klingshirn, Appl. Phys. Lett. 92, 211105 (2008).

${ }^{68}$ H. Shibata, Jpn. J. Appl. Phys. 37, 550 (1998).

${ }^{69}$ R. Chen, B. Ling, X. W. Sun, and H. D. Sun, Adv. Mater. 23, 2199 (2011).

${ }^{70}$ R. Aad, C. Couteau, and G. Lérondel, Materials 8, 1682 (2015).

${ }^{71}$ H. He, Q. Yang, C. Liu, L. Sun, and Z. Ye, J. Phys. Chem. C 115, 58 (2011).

${ }^{72}$ S. Vempati, J. Mitra, and P. Dawson, Nanoscale Res. Lett. 7, 470 (2012).

${ }^{73}$ H. Q. Wang, G. Z. Wang, L. C. Jia, C. J. Tang, and G. H. Li, J. Phys. D 40, 6549 (2007). 